International Journal of Trend in Scientific Research and Development (IJTSRD)

Volume: 3 | Issue: 3 | Mar-Apr 2019 Available Online: www.ijtsrd.com e-ISSN: 2456 - 6470

\title{
Multi-Operational Machining and Controlling with the Help of Electro-Magnetic Clutch
}

\author{
Dr. Rahul Saini', Mr. Naveen Kumar', Desh Deepak², Ashutosh Kushwaha², Ambrish Pandey² \\ ${ }^{1}$ Assistant Professor, ${ }^{2}$ Student \\ 1,2ABES Engineering College, Ghaziabad, India
}

\begin{abstract}
How to cite this paper: Dr. Rahul Saini | Mr. Naveen Kumar | Desh Deepak | Ashutosh Kushwaha | Ambrish Pandey "Multi-Operational Machining and Controlling with the Help of ElectroMagnetic Clutch" Published in International Journal of Trend in Scientific Research and Development (ijtsrd), ISSN: 24566470, Volume-3 | Issue-3, April 2019, pp.1018-1021, URL: https://www.ijtsrd.c om/papers/ijtsrd23 181.pdf

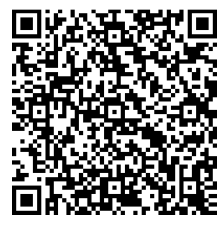

Copyright (C) 2019 by author(s) and International Journal of Trend in Scientific Research and Development Journal. This is an Open Access article distributed under the terms of the Creative Commons

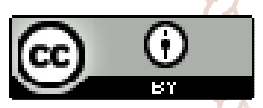
Attribution License (CC BY 4.0) (http://creativecommons.org/licenses/ by $/ 4.0$ )
\end{abstract} ABSTRACT

The whole concept of multi-operational machining and controlling with the help of electro-magnetic clutch revolves around the small scale and medium scale production industries. The idea is to reduce the floor space and cost of the machineries as well as power consumption also has to be reduce for better controlling of the machine parts the electro-magnetic clutch is also provided. The proposed model is capable of sawing(cutting),drilling and grinding with the help of dc motor. In this model all the operations can be done individually as well as simultaneously. In future scope individual speed controller can also be provided with the help of programmable motherboards.

\section{Introduction}

The fundamental reason behind the design of this machine is that to make a fully clutch controlled, less power consuming, multi-operational machine that could perform more than one operation simultaneously as well as individually. previously such types of machines has been designed[1] but those are not capable of performing single operation

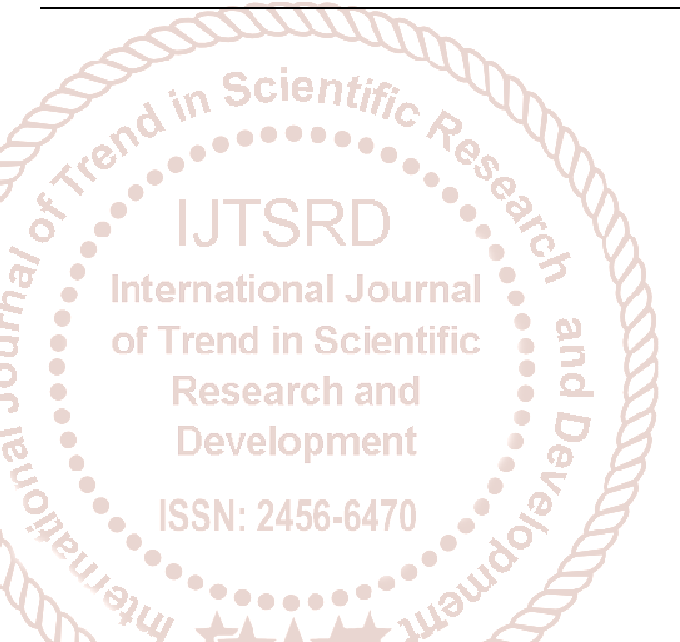

individually as clutch system was not present. Due to this reason there was more power loss as we know that all the operations are not required simultaneously all the time. So, if any of the operations are not required there was no provision of stopping that operation.

\section{Literature review}

\begin{tabular}{|c|c|c|c|c|}
\hline YEAR & AUTHOR & OBJECTIVE & CONCLUSION \\
\hline 2001 & $\begin{array}{c}\text { Arnold and } \\
\text { Heinrich[3] }\end{array}$ & $\begin{array}{c}\text { History of } \\
\text { machine tools } \\
\text { and recent } \\
\text { changes. }\end{array}$ & $\begin{array}{c}\text { In recent 15 years there has been increased advancement in the machine } \\
\text { instrument industry as old models are persistently being supplanted by } \\
\text { new ones. the joining of computerized controls innovation and PCs into } \\
\text { machine apparatuses has influenced the business in these regions. Most } \\
\text { organizations thought little of the effect of this new innovation. }\end{array}$ \\
\hline 2006 & $\begin{array}{c}\text { Dr. } \\
\text { Toshimichi } \\
\text { Moriwaki[4] }\end{array}$ & $\begin{array}{c}\text { Recent trends in } \\
\text { machine tools. }\end{array}$ & $\begin{array}{c}\text { Machine device advances are studied from the view purpose of fast and } \\
\text { elite machine devices, consolidated multifunctional machine apparatuses, } \\
\text { high exactness machine devices and progressed and smart control } \\
\text { advances. }\end{array}$ \\
\hline 2011 & $\begin{array}{c}\text { Frankfurt-am } \\
\text { Main[5] }\end{array}$ & $\begin{array}{c}\text { Multi-purpose } \\
\text { machining }\end{array}$ & $\begin{array}{c}\text { Machine tools nowadays must be able to handle all kinds of materials, and } \\
\text { offer maximum flexibility. Two of the exceptionally regarded specialists } \\
\text { on machining and shaping namely Dortmund and Chemnitz report on } \\
\text { what's coming up for machine instrument makers and clients. The } \\
\text { ongoing pattern requests for multi-operational machining focuses that } \\
\text { can deal with a wide arrangement of items with little group sizes. }\end{array}$ \\
\hline
\end{tabular}


International Journal of Trend in Scientific Research and Development (IJTSRD) @ www.ijtsrd.com eISSN: 2456-6470

\begin{tabular}{|c|c|c|c|}
\hline 2014 & $\begin{array}{l}\text { Sharad } \\
\text { srivastava[2] }\end{array}$ & $\begin{array}{l}\text { Model } \\
\text { conceptualization }\end{array}$ & $\begin{array}{l}\text { Growing generation based ventures needed low creation cost and large } \\
\text { production which can be achieved by the use of multi-operational } \\
\text { working machine which consumes less power as well as time, since this } \\
\text { machine gives working at } \\
\text { diverse focus it truly diminished the time utilization } \\
\text { up as far as possible. }\end{array}$ \\
\hline 2015 & $\begin{array}{c}\text { Rakesh } \\
\text { Ambade[6] }\end{array}$ & $\begin{array}{l}\text { Design and } \\
\text { fabrication }\end{array}$ & $\begin{array}{c}\text { Developing a machine which can work effectively in the remote areas } \\
\text { where power supply is often irregular. machine can perform light } \\
\text { operation with semi skilled workers also expert workers are not } \\
\text { required. }\end{array}$ \\
\hline 2016 & $\begin{array}{l}\text { M. } \\
\text { Prathyusha } \\
{[13]}\end{array}$ & $\begin{array}{l}\text { Theoretical } \\
\text { explanation of } \\
\text { multi-purpose } \\
\text { machines. }\end{array}$ & $\begin{array}{l}\text { Different developments has been explained so that multi-purpose } \\
\text { machines can be adopted effectively and efficiently. }\end{array}$ \\
\hline 2018 & $\begin{array}{l}\text { Yashraj V. } \\
\text { Patil } \\
\text { [14] }\end{array}$ & $\begin{array}{l}\text { Multi-purpose } \\
\text { tool fabrication }\end{array}$ & $\begin{array}{l}\text { In multipurpose tooling machine, industrialists will spend less cash on } \\
\text { hardware when contrasted with individual machines for the same } \\
\text { activities. Additionally the floor space required to setup this machine is } \\
\text { additionally exceptionally less as opposed to setting up singular } \\
\text { machines, the power utilization will likewise be decreased impressively }\end{array}$ \\
\hline 2018 & $\begin{array}{c}\text { Aquib } \\
\text { Ahmad[1] }\end{array}$ & $\begin{array}{l}\text { Model } \\
\text { conceptualization } \\
\text { and } \\
\text { mathematical } \\
\text { calculations. }\end{array}$ & $\begin{array}{l}\text { Design a machine which performs activity such as cutting, grinding and } \\
\text { drilling on various work focuses at the same time which infers that } \\
\text { speculation isn't required for machines. Likewise, floor required to setup } \\
\text { this machine is less when contrasted with floor required for setting up } \\
\text { individual machines which suggests an extremely straightforward item } \\
\text { format. }\end{array}$ \\
\hline
\end{tabular}

\section{METHODOLOGY USED}

The basic working of this project starts with a step down transformer $(220 \mathrm{~V} \sim 12 \mathrm{~V})$ then alternating current is changed to direct current using p-n junction diode and capacitor. after this a switch is placed this controls the power supply to the DC motor (12V \& $1000 \mathrm{rpm})$ the three switches is connected to the three different electro-magnetic clutches. these clutches controls the three different mechanical operations namely cutting(sawing),drilling and grinding.

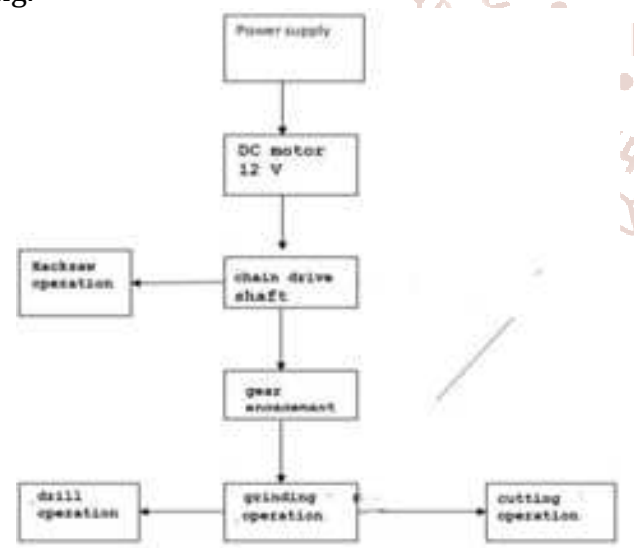

FIG. 1 FLOW DIAGRAM THE PROCESS[1]

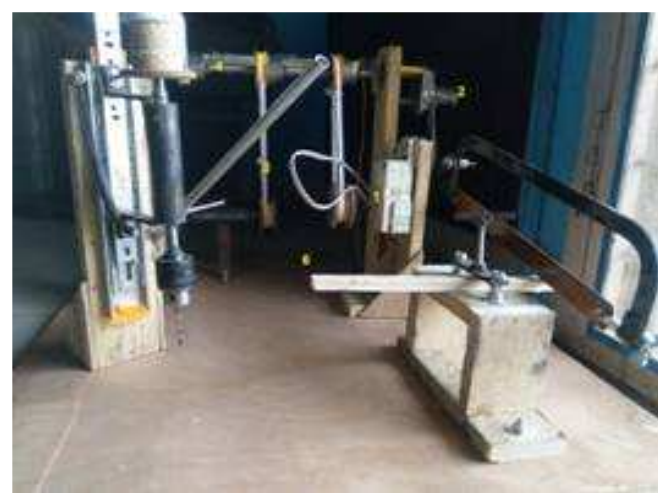

FIG. 2 CONCEPTUAL MODEL

\section{A. SAWING}

The sawing operation draws the power as the electromagnetic clutch engages the power is then transferred to a gear assembly with the gear ratio of $(54: 32)$ in order to reduce the speed and increase the torque output. The torque generated uses the scotch - yoke mechanism and changes the rotational motion into the linear cutting operation.

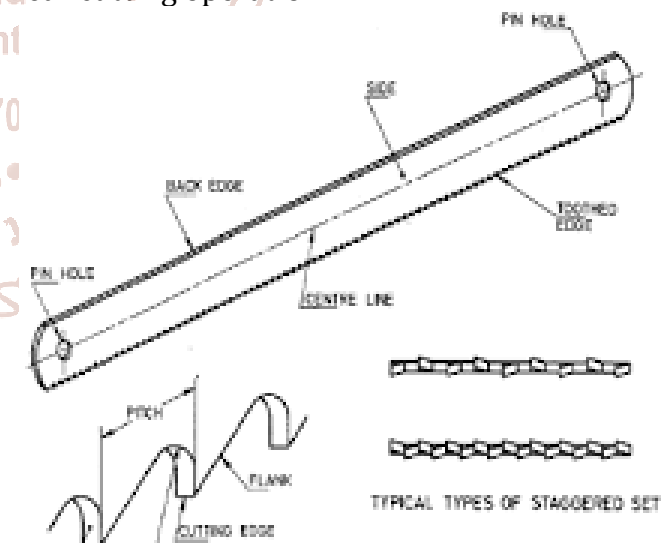

FIG. 3 SAWING DIAGRAM.[15]

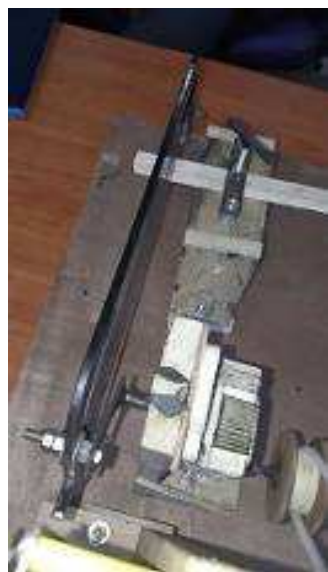

FIG. 4 SAWING OPERATION 


\section{ELECTRO-MAGNETIC CLUTCH}

Electromagnetic grasps work by means of an electric activation yet transmit torque precisely. At the point when current moves through the grasp curl, the loop turns into an electromagnet and produces attractive lines of transition. This motion is then exchanged through the little hole between the field and the rotor.[7]

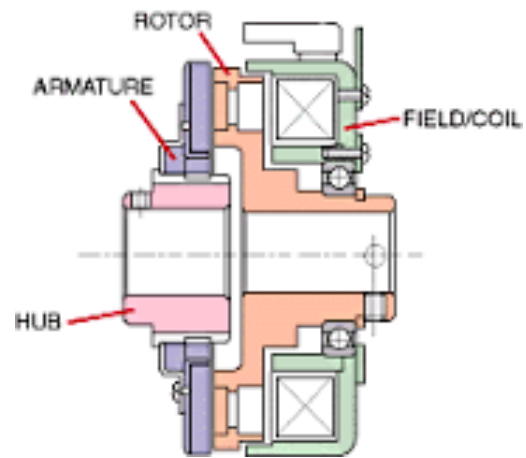

FIG. 5 ELECTRO-MAGNETIC CLUTCH(DIAGRAM)[7]

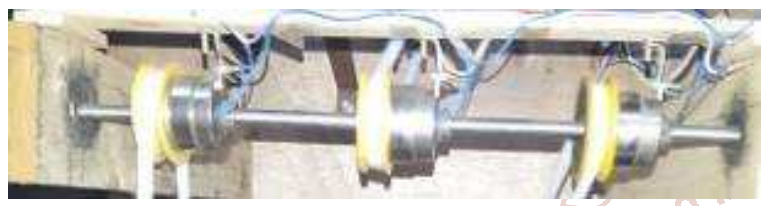

FIG.6 ELECTRO-MAGNETIC CLUTCH

\section{SCOTCH-YOKE MECHANISM}

Scotch-yoke mechanism in our project is used to convert the torque generated by the gear-box assembly into to and fro (linear) motion of the hacksaw. In previous work [1] single slider mechanism is used but we are using scotch-yoke mechanism as it has further benefits like more than one hacksaw can be used in the future.

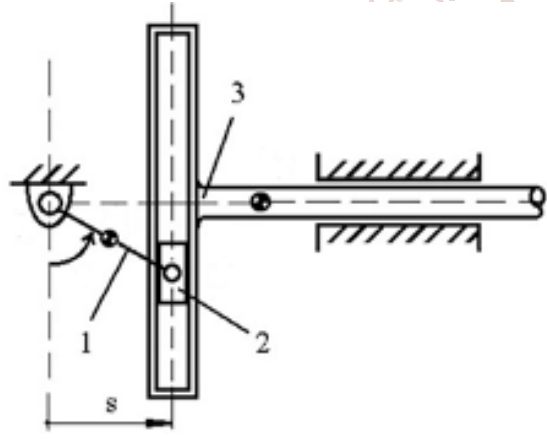

FIG.7 SCOTCH-YOKE MECHANISM [9]

Here,

1. Crank pin

2. Slider

3. Reciprocating part(Piston)

\section{B. DRILLING}

Nowadays drilling is one of the most common practice in industries. it is the process of making holes of the desired size. The drill bit is held in the shank and tip of the tool rotates. the chips comes out with the help of flute which are grooved in the drill bit.[10]Drills are regularly utilized in carpentry, metalworking and development. Uncommonly planned drills are additionally utilized in drug, interplanetary missions and different applications. A velocity regulator will be placed in order to change the speed of the drill-bit according to the material in future versions of the machine.

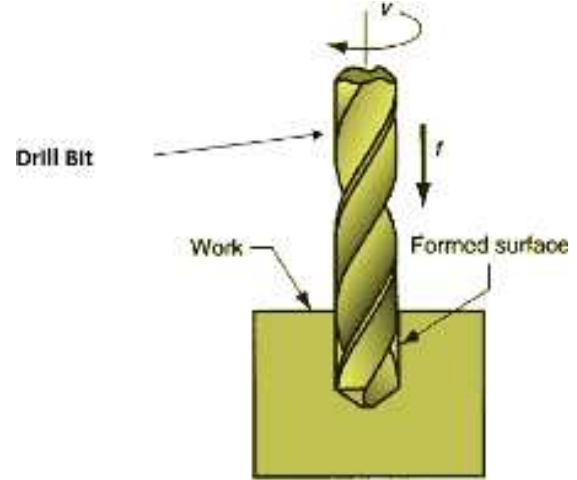

FIG.8 DRILLING (DIAGRAM) [11]

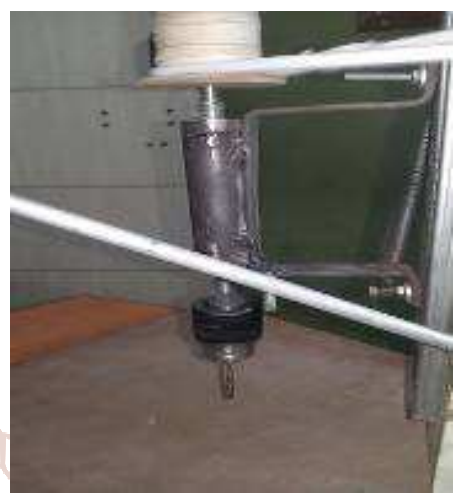

FIG.9 DRILLING
C. GRINDING

Grinding is a machining procedure that utilizes an instrument made up of grating powder. Fundamental point of grinding process isn't to evacuate material; however to accomplish or control measurements inside close resilience; or to accomplish great surface completion which is generally hard to accomplish by conventional material removing machines.In our project we are using low to medium speed grinding which varies from $0.3 \mathrm{~m} / \mathrm{s}$ to $10 \mathrm{~m} / \mathrm{s}$.Low speed grinding can be used for harden gear materials and medium speed can be used for grinding purpose.

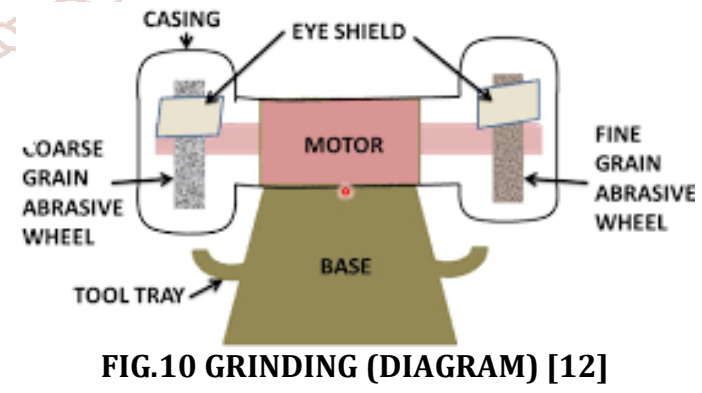

4. COMPONENTS USED

\begin{tabular}{|c|c|c|}
\hline Sr. & Equipment & Quantity \\
\hline & Capacitor 1000uf for filter voltage & 1 \\
\hline 5 & Wood & 1 \\
\hline 6 & Clamp & 4 \\
\hline 7 & Transformer & 1 \\
\hline 8 & Dc motor & 1 \\
\hline 9 & Drill & 1 \\
\hline 10 & Diode & 4 \\
\hline 11 & Wire & 1 \\
\hline 13 & Electromagnetic clutch & 3 \\
\hline 14 & Metallic Screw & 6 \\
\hline 15 & Switch & 4 \\
\hline
\end{tabular}




\section{CONCLUSION}

We can clearly see that with growing demand and competition in the market we need to move towards the machines which are efficient, less power consuming as well as multi-purpose. Here, is the idea of making such machines with the introduction of Electro-magnetic clutch that will provide better control to each of the components and saves power where it is required. The electro-magnetic clutch turns of the power supply when the machine is not working. The system is designed for performing three machining operations. which uses DC power supply (it means that it can be used in those areas where is lack of power supply with the help of batteries).It is more power efficient as compared to those of the previous versions as the power is supplied to only those component which requires power. It is cheaper than conventional machines and requires less floor area.

\section{REFRENCES:-}

[1] Aquib Ahmad "Multi Operational Mechanical Machine", IRJET Volume:05 Issue: 04,2018

[2] Sharad Srivastava "Multi-function operating machine: A conceptual model”, IOSR-JMCE Volume: 11 Issue: 03 May-June 2014.

[3] Arnold, Heinrich "The recent history of the machine tool industry and the effects of technological change", University of Munich, Institute for Innovation Research and Technology Management, November 2001.
[4] Dr. Toshimichi Moriwaki "Trends in Recent Machine Tool Technologies",2006

[5] Frankfurt am Main "Multi-purpose machines ensure enhanced ", 1 January 11.

[6] Rakesh Ambade "Design \& fabrication of human powered multi-purpose machine”, IJATES Volume: 03 Special. issue: 01 April 2015.

[7] https://en.wikipedia.org/wiki/Electromagnetic_clutch

[8] https://en.wikipedia.org/wiki/Scotch_yoke

[9] https://www.researchgate.net/figure/Scotch-yokemechanism_fig1_284175995

[10] https://en.wikipedia.org/wiki/Drilling

[11] http://www.mechscience.com/drilling-and-relatedoperations-drilling-process-types-of-drilling-process/

[12] https://www.youtube.com/watch?v=QMEiPdtES58

[13] M. Prathyusha "Multiple operating machines (drilling, sawing, shaping)”, IJMETMR Volume: 03 Issue: 05 May 2016.

[14] Yashraj V patil "Study of Fabrication of Multipurpose Tooling Machine", IRJET Volume: 05 Issue: 03 March 2018

[15] https://www.researchgate.net/figure/HacksawBlade_fig1_281715377 